\title{
Hepatic Perforation: A Complication of Proximal Biliary Stent Migration
}

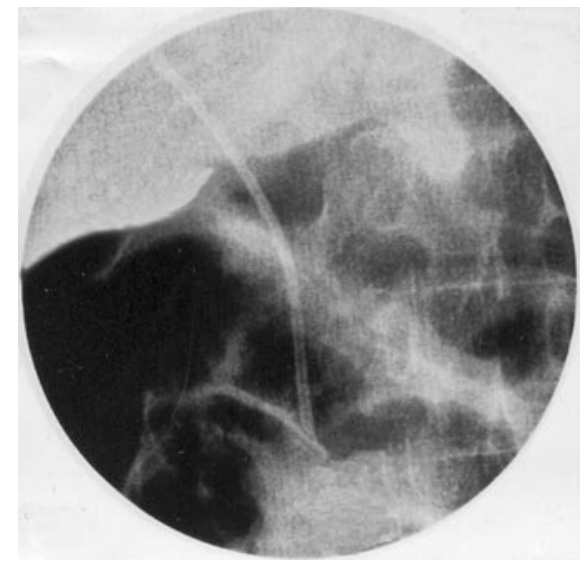

Figure 1 Radiograph of the right upper abdomen showing a migrated stent with dilated loops of intestine.

\section{J. Shah', F. A. Khan', I. Robanni², N. A. Wani ${ }^{1}$}

${ }^{1}$ Department of Surgery, Sher-I-Kashmir Institute of Medical Sciences, Srinagar, Kashmir, India

\section{Corresponding Author}

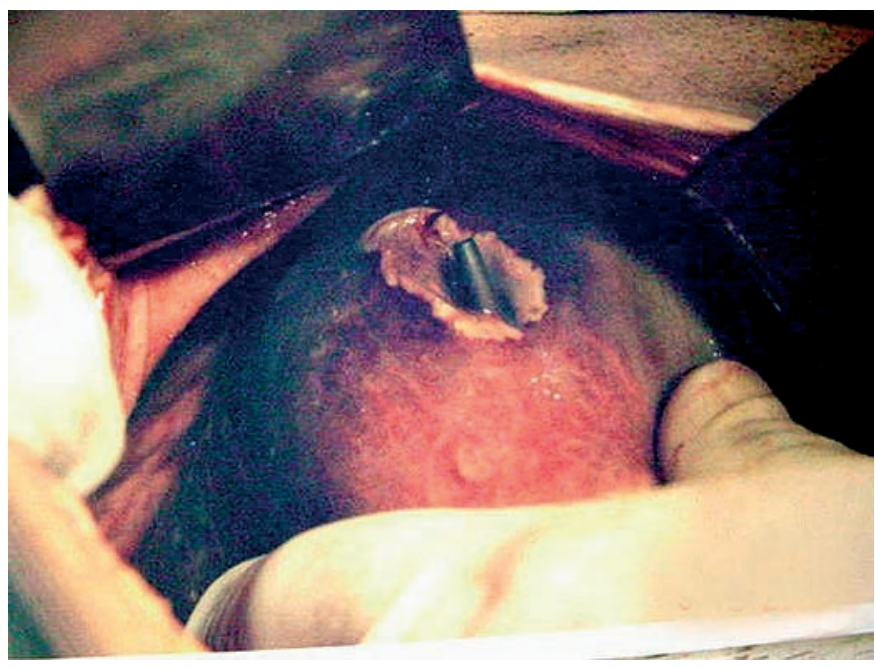

Figure 2 Peroperative photograph showing the hepatic perforation in the anterosuperior part of the right lobe of the liver caused by the migrated stent.

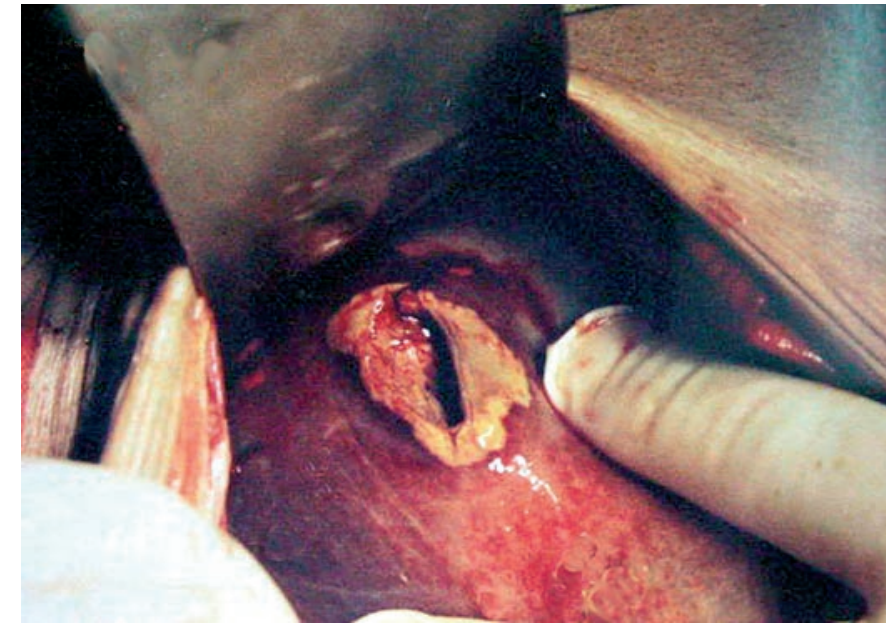

Figure 3 Close-up peroperative view of the hepatic perforation seen in Figure $\mathbf{2}$. Note the size of the perforation.

\section{O. J. Shah, M.D.}

Kral-Sangri

Brain, Nishat

Srinagar

Kashmir

India

Fax: +91-194-2403470

E-mail: omarjshah@yahoo.com 